\title{
Dioxins: source, origin and toxicity assessment
}

\begin{abstract}
Persistent, bioaccumulative and toxic chemicals (PBTs) are substances that can build up to levels that can be harmful to human and ecological health. These contaminants may travel long distances in the atmosphere and can move readily from land to air and water. The accumulation of such chemicals in organisms from the surrounding environment through absorption, ingestion and inhalation may cause severe health issues. Dioxin is formed as an unintentional by-product of many industrial processes involving chlorine such as waste incineration, chemical and pesticide manufacturing, treatment of hazardous material and pulp and paper bleaching. The potential for health risks due to the cancer-promoting, immunomodulating and teratogenic activities of dioxins in rodents has raised concerns over their presence in the human food chain. There is an urgent need of taking attention on sources of emission of dioxin and its mitigation measures. In this chapter, the sources, its origin and toxicity assessment of dioxin has been presented along with 3 case studies.
\end{abstract}

Keywords: dioxin, epa, toxic equivalents, bioaccumulation, immunoglobulin
Volume 2 Issue 4 - 2018

\author{
Ashok K Rathoure \\ Eco Chem Sales \& Services, Ecosystem Resource Management \\ Pvt Ltd, India
}

Correspondence: Ashok K Rathoure, Mayashivraj Sadan, Gupta Colony, Hardoi-24I00I (UP) India,Tel +9I-945050 I47I, Email asokumr@gmail.com

Received: December 08, 2017| Published: July 06, 2018

\section{Introduction}

The term dioxin refers to a group of chemical compounds sharing certain similar structures and biological characteristics. ${ }^{1}$ Dioxin is the common name for 2,3,7,8-tetrachlorodibenzo-para-dioxin (TCDD) but is also used for the structurally and chemically related polychlorinated dibenzo-para-dioxins (PCDD), dibenzofurans (PCDF) and the coplanar polychlorinated biphenyls (PCB). There are 75 PCDD congeners, 135 PCDF and 209 PCB. Seven PCDD and 10 PCDF with substitutions at the 2,3,7 and 8 positions are considered toxic and 11 PCB have dioxin-like toxicity. Dioxin compounds are not created intentionally, but are formed inadvertently by a number of human and natural activities. These activities include combustion and incineration, forest fires, chlorine bleaching of pulp and paper, certain types of chemical manufacturing and processing and other industrial processes. $^{2}$ Many forms of dioxin exist. One form, 2,3,7,8-tetrachlorodibenzo-p-dioxin (2,3,7,8-TCDD) is considered the most toxic form. It is also the most studied form. Toxic equivalents (TEQs) are used to describe the toxicity of 16 other forms relative to $2,3,7,8$ TCDD. Persistent, bioaccumulative and toxic chemicals (PBTs) are substances that can build up to levels that can be harmful to human and ecological health. These contaminants may travel long distances in the atmosphere and can move readily from land to air and water. Bioaccumulation is the accumulation of chemicals in organisms from the surrounding environment through absorption, ingestion and inhalation. ${ }^{3}$ Dioxins dissolve more easily or are more attracted to oily or fatty compounds than water. Because of this, they are more prevalent in animals with body fat, soils and sediments than they are in water. The same goes for other wildlife. Dioxin works its way to the top of the food chain. Dioxin was the primary toxic component of Agent Orange, was found at Love Canal in Niagara Falls, NY and was the basis for evacuations at Times Beach, MO and Seveso, Italy (Table 1).

\section{Source and origin of dioxins}

The majority of toxic dioxin is and has been derived from industrial chlorination processes, incineration of municipal waste and production of certain herbicides. The toxicity of other dioxins and chemicals like
PCBs that act like dioxin are measured in relation to TCDD. Dioxin is formed as an unintentional by-product of many industrial processes involving chlorine such as waste incineration, chemical and pesticide manufacturing and pulp and paper bleaching. Dioxin is formed by burning chlorine-based chemical compounds with hydrocarbons. The major source of dioxin in the environment comes from waste-burning incinerators of various sorts and also from backyard burn-barrels. Dioxin pollution is also affiliated with paper mills which use chlorine bleaching in their process and with the production of Polyvinyl Chloride (PVC) plastics and with the production of certain chlorinated chemicals like many pesticides. The major sources of dioxin are in our diet. Since dioxin is fat-soluble, it bioaccumulates, climbing up the food chain. A North American eating a typical North American diet will receive $93 \%$ of their dioxin exposure from meat and dairy products $(23 \%$ is from milk and dairy alone; the other large sources of exposure are beef, fish, pork, poultry and eggs). In fish, these toxins bioaccumulate up the food chain so that dioxin levels in fish are 100,000 times that of the surrounding environment. Dioxin is released by paper mills, by metal smelters, by many chemical plants, by many pesticide factories and by all incinerators.

\section{Dioxin formation in cement kilns}

The long residence time and high temperature in the cement kiln as compared with municipal waste incinerators lead to very low amount of PCDD/Fs. In fact, PCDD/Fs and other components of hazardous waste may actually be destroyed properly in cement kilns if added directly to the burner. ${ }^{4}$ Majority of the research done on formation of dioxins in cement kilns suggest that these compounds mainly are formed at the cooler parts of the processes, including the preheater region (red colour zone) and post preheater region (blue colour zone). The destruction of hazardous waste in cement kilns, including chlorinated hydrocarbons have been analyzed by many researchers and found more than $99.99 \%$ destruction efficiency. ${ }^{5,6}$ Due to high temperature in cement kilns, all the organics are destroyed, therefore formation of dioxins in cement kilns may be attributed to the preheater zone and post preheater zone. In the preheater region (red), raw meal is added, heated with the hot gas coming from rotary kiln and calcination occurs in this region. The temperature in this region varies 
from approximately $250-850^{\circ} \mathrm{C}$ with lower part of pre heater zone at higher temperature and upper part at lower temperature. The raw meal may constitute many particle surfaces, which may facilitate the surface catalyzed formation of PCDD/Fs. ${ }^{7}$ At the same time, the lower part of preheater zone may facilitate the homogeneous gas phase formation and upper part may participate in heterogeneous formation of dioxins. The organic material present in the raw meal, volatilize in the preheater zone and become available in the gas stream. Usually there is enough chlorine present in the raw meal to maintain the formation reactions of the chlorinated organic compounds (chlorophenols, chlorobenzene etc.) needed for PCDD/Fs formations. ${ }^{8}$ The raw gas (kiln gas), may contain carbon residues and deposited on surfaces of the walls of air pollution control devices (APCD) blue colour region. The temperature and oxygen concentration may also be responsible for the formation of dioxins in APCD. APCD such as electrostatic precipitator (ESP) is used in cement industries to remove the particulate matter from the flue gas. This particulate matter may adsorb some dioxins on their surfaces.

Table I Nomenclature for dioxin-like compounds

\begin{tabular}{|c|c|}
\hline $\begin{array}{l}\text { Term/ } \\
\text { Symbol }\end{array}$ & Definition \\
\hline Congener & $\begin{array}{l}\text { Any one particular member of the same chemical family, } \\
\text { e.g. there are } 75 \text { congeners of chlorinated dibenzo-p- } \\
\text { dioxins. }\end{array}$ \\
\hline Homologue & $\begin{array}{l}\text { Group of structurally related chemicals that have the } \\
\text { same degree of chlorination. For example, there are } \\
\text { eight homologues of CDDs, monochlorinated through } \\
\text { octochlorinated. }\end{array}$ \\
\hline Isomer & $\begin{array}{l}\text { Substances that belong to the same homologous class. } \\
\text { For example, there are } 22 \text { isomers that constitute the } \\
\text { homologues of TCDDs. }\end{array}$ \\
\hline $\begin{array}{l}\text { Specific } \\
\text { congener }\end{array}$ & $\begin{array}{l}\text { Denoted by unique chemical notation. For example, } \\
2,4,8,9 \text {-tetrachlorodibenzofuran is referred to as } 2,4,8,9- \\
\text { TCDF. }\end{array}$ \\
\hline D & Symbol for homologous class: dibenzo-p-dioxin \\
\hline $\mathrm{F}$ & Symbol for homologous class: dibenzofuran \\
\hline M & Symbol for mono, i.e. one halogen substitution \\
\hline $\mathrm{D}$ & Symbol for di, i.e. two halogen substitution \\
\hline $\operatorname{Tr}$ & Symbol for tri, i.e. three halogen substitution \\
\hline $\mathrm{T}$ & Symbol for tetra, i.e. four halogen substitution \\
\hline $\mathrm{Pe}$ & Symbol for penta, i.e. five halogen substitution \\
\hline $\mathrm{Hx}$ & Symbol for hexa, i.e. six halogen substitution \\
\hline $\mathrm{Hp}$ & Symbol for hepta, i.e. seven halogen substitution \\
\hline $\mathrm{O}$ & Symbol for octa, i.e. eight halogen substitution \\
\hline CDD & $\begin{array}{l}\text { Chlorinated dibenzo-p-dioxins, halogens substituted in } \\
\text { any position }\end{array}$ \\
\hline CDF & $\begin{array}{l}\text { Chlorinated dibenzofurans, halogens substituted in any } \\
\text { position }\end{array}$ \\
\hline PCB & Polychlorinated biphenyls \\
\hline
\end{tabular}

Source: EPA, 1989
In modern preheater kilns, the emission is lower because of lower temperature of APCD. The raw gases from the rotary kilns go through the preheater then through raw mill dryer to heat the raw meal, enter into APCD and then stack gas. This operational mode decreases the hot gas temperature and increase the possibility for adsorption of PCDD/ Fs in APCD. Due to lower temperature and adsorption of PCDD/Fs, low level of dioxins detected in stack gas. On the other hand, some studies show that there are more chances for the formation of dioxins in APCD, due to adsorption of carbon structures and temperature profile almost $250-350^{\circ} \mathrm{C} .^{9}$

Karstensen et al., ${ }^{6}$ identified the following main sources for the dioxins emissions in cement kilns:

i. Raw meal, containing naturally occurring PCDD/Fs

ii. $\mathrm{PCDD} /$ Fs formed in the preheater zone

iii. $\mathrm{PCDD} / \mathrm{Fs}$ associated with cement kiln dust (CKD), originating from the ESP.

Cement kiln dust (CKD) containing adsorbed dioxins collected and reintroduced into the process along with raw meal. Karstensen et al., ${ }^{6}$ proposed that there is region between ESP and preheater region where $\mathrm{PCDD} / \mathrm{Fs}$ produced and are present in gaseous as well as adsorbed form. Once dioxins are produced, they will circulate between gaseous and particle adsorbed form. ${ }^{10}$ Hence, in cement industry dioxins formation could be attributed to the already dioxins present in the raw meal and the combination of homogeneous and heterogeneous mechanism in the preheater and post combustion zone for the formation of PCDD/Fs are significant. ${ }^{11}$ Homologue profile or congener pattern of dioxins within each homologue group may be used to identify the major sources and formation pathways, responsible to the dioxins formation in a specific case. Homologue profile provides the information about the relative proportions of mono to Oct-chlorinated compounds and simply described as a single number indicating the average degree of chlorination. The degree of chlorination varies between 1 and 8 , where 8 indicates the PCDD or PCDF as OCDD or OCDF. Some studies show that homologue profile differs if there are changes in fuel composition and combustion conditions.

\section{Dioxin and health}

The potential for health risks due to the cancer-promoting, immunomodulating and teratogenic activities of dioxins in rodents has raised concerns over their presence in the human food chain. The lipophilic nature of dioxins results in higher concentrations in the fat of animal and fish products and their excretion via milk secretion in dairy cattle may result in relatively high concentrations of dioxin contamination in high-fat dairy products. Surface contamination of plant foods and soil due to deposition of atmospheric emissions may also be a significant direct source of dioxin ingestion for livestock and thereby an indirect source of dioxin for humans. Despite numerous epidemiological studies, dioxin has not been conclusively determined to be problematic for humans. Certain management practices such as trimming fat from meat, consuming low-fat dairy products and simply cooking food can substantially decrease exposure to dioxin compounds. The EPA report confirmed that dioxin is a cancer hazard to people. In 1997, the International Agency for Research on Cancer (IARC), part of the World Health Organization, published their research into dioxins and furans and announced on February 14, 1997, that the most potent dioxin, 2,3,7,8-TCDD, is a now considered 
a Group 1 carcinogen, meaning that it's a known human carcinogen. In addition to cancer, exposure to dioxin can also cause severe reproductive and developmental problems at levels 100 times lower than those associated with its cancer causing effects. Dioxin is wellknown for its ability to damage the immune system and interfere with hormonal systems. Dioxin exposure has been linked to birth defects, inability to maintain pregnancy, decreased fertility, reduced sperm counts, endometriosis, diabetes, learning disabilities, immune system suppression, lung problems, skin disorders, lowered testosterone levels and much more.

A very large proportion of dioxin comes from human sources. Dioxin began accumulating in the environment around 1900 when the founder of Dow Chemical (Midland, Michigan) invented a way to split table salt into sodium atoms and chlorine atoms, thus making large quantities of free chlorine available for the first time. The dioxin is toxic to humans in surprisingly many ways and that the general public is not adequately protected from ill effects by a traditional margin of safety. Chloracne was the first disease associated with exposure to dioxin, first described in 1897. Chloracne appeared as an occupational problem in the 1930s among pesticide workers and among workers who manufactured industrial chemicals called PCBs (polychlorinated biphenyls). However, dioxin was not identified as the cause of chloracne until about 1960. (Dioxin was an unwanted contaminant of the pesticides and PCBs.) Chloracne produces skin eruptions, cysts and pustules like a very bad case of teenage acne; except that the sores can occur all over the body and in serious cases can last for many years.

Male body has no ways to get rid of dioxin other than letting it break down according to its chemical half-lives. Female, on the other hand, have two ways which it can exit their bodies:

a. It crosses the placenta into the growing infant;

b. It is present in the fatty breast milk, which is also a route of exposure which doses the infant, making breast-feeding for nonvegan/vegetarian mothers quite hazardous (Figure 1).

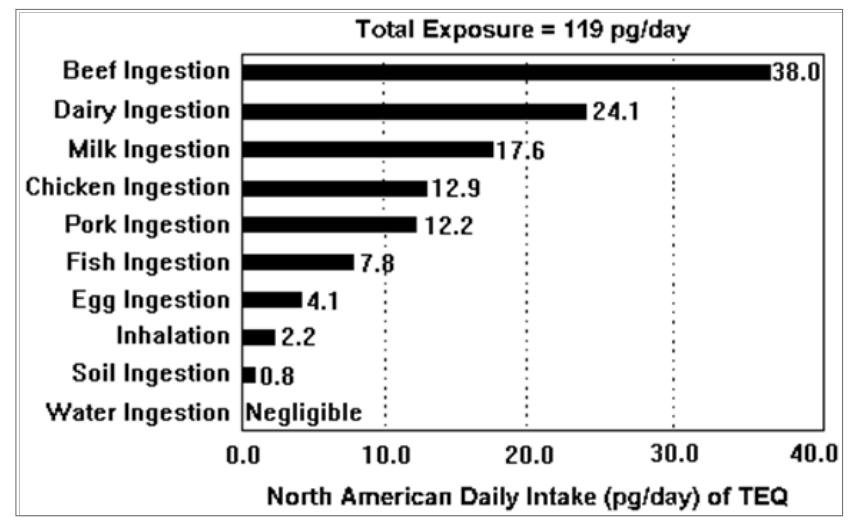

Figure I Dioxin Reassessment by EPA.

A TEQ is a dioxin Toxic Equivalent, calculated by looking at all toxic dioxins and furans and measuring them in terms of the most toxic form of dioxin, 2,3,7,8-TCDD. This means that some dioxins/ furans might only count as half a TEQ if it's half as toxic as 2,3,7,8TCDD. Researchers at the National Institute of Occupational Safety and Health (NIOSH) found reduced levels of testosterone (male sex hormone) circulating in the blood of dioxin-exposed male workers. Other sex hormone levels in these men were affected as well. The body burdens that seem to produce an increase in diabetes range from 99 to $140 \mathrm{ng} / \mathrm{kg}$. Thus the average American, with a body burden of $13 \mathrm{ng} / \mathrm{kg}$, is a factor of 8 below the lowest level thought to create a diabetes hazard. Dioxin is an astonishingly versatile and potent poison.

EPA $^{12}$ characterizes 2,3,7,8-TCDD as a human carcinogen based on the weight of evidence of animal and human studies and characterizes other dioxin like compounds i.e. other dioxin-like chlorinated dibenzop-dioxins [CDDs] and chlorinated dibenzofurans [CDFs] and dioxinlike polychlorinated biphenyls [PCBs]; as likely human carcinogens. The US Department of Health and Human Services determined that it is reasonable to expect that 2,3,7,8-TCDD may cause cancer. ${ }^{13}$ The International Agency for Research on Cancer determined that 2,3,7,8TCDD is a known human carcinogen. ${ }^{14}$ Possible human health effects associated with endocrine disruption may include breast cancer and endometriosis in women, testicular and prostate cancers in men, abnormal sexual development, reduced male fertility, alteration in pituitary and thyroid gland functions, immune suppression and neurobehavioral effects. ${ }^{15}$ Although birth defects have been observed in animals (developing animals are especially sensitive) exposed to higher than background levels of 2,3,7,8-TCDD, human birth defects resulting from exposure to dioxins currently cannot be confirmed. ${ }^{13}$

\section{Dioxin toxicity assessment}

The study was undertaken by Latchoumycandane \& Mathur ${ }^{16}$ to investigate whether treatment with vitamin $\mathrm{E}$ protects rat testis from oxidative stress induced by 2,3,7,8-tetrachlorodibenzo-p-dioxin (TCDD). Male rats of Wistar strain were administered TCDD at doses of 1, 10 and 100ng per kg body wt. per day for 45 days. Other groups of animals were co-administered TCDD (1, 10 and 100ng per $\mathrm{kg}$ body wt. per day) and vitamin E (20mg per kg body wt. per day) for 45 days. Animals administered TCDD and those co-administered TCDD and vitamin E did not show any significant change in body weight. Administration of TCDD decreased the weights of the testis, epididymis, seminal vesicles and ventral prostate. The daily sperm production decreased in the animals administered TCDD from the control values of $22.19+/-2.67$ to $13.10+/-3.16 \times 10^{6}$. There was a significant decline in the activities of superoxide dismutase, catalase, glutathionereductase and glutathione peroxidase with concomitant increased levels of hydrogen peroxide and lipid peroxidation. Coadministration of TCDD and vitamin E did not show any significant changes in the weights of the testis, epididymis, seminal vesicles and ventral prostate. The daily sperm production remained unchanged in the animals co-administered TCDD and vitamin E. The activities of antioxidant enzymes and the levels of hydrogen peroxide and lipid peroxidation did not change in the animals co-administered TCDD and vitamin E. These results suggested that administration of TCDD induces oxidative stress in testis and vitamin $\mathrm{E}$ could impart a protective effect against TCDD-induced oxidative stress. ${ }^{17}$

The toxicity of TCDDis mediated by activation of the aryl hydrocarbon receptor (AhR), an orphan receptor belonging to the basic helix-loop-helix Per-ARNT-Sim family of transcription factors. TCDD and related chemicals bind to the AhR with high affinity, leading to its translocation into the nucleus and dimerization with the AhR nuclear translocator (ARNT). This heterodimeric complex then binds dioxin response elements in the promoters of target genes and regulates their transcriptional expression. ${ }^{18}$ Mice in which the AhR 
has been genetically deleted fail to exhibit any overt toxic responses typically observed after TCDD exposure, ${ }^{19-24}$ demonstrating that AhR activation is required to mediate TCDD toxicity.

\section{Case studies on dioxin}

\section{Case-I: Land fill site at Sachin, Surat (Gujarat)}

Hazardous wastes may be detrimental to both human health and day to day human life. Components of hazardous waste can be carcinogenic, teratogenic, corrosive, flammable, explosive and/or releasing toxic fumes. The industries/government need technically feasible and sustainable solutions for the management of hazardous waste generated. Gujarat Enviro Protection and Infrastructure Limited have set up Integrated Common Hazardous Waste Management Facility for the treatment, storage and disposal of Hazardous Wastes generated by the cluster of Industries in the Surat region. GEPIL has been established in 1999 .

The dioxins are released during the treatment of hazardous chemicals. In purview of that, some NGOs had discussion with proponent about the release of toxic gases from the unit and proponent assured for taking care of any gaseous release. On $17^{\text {th }}$ Jan. 2012, thousands of people from over 30 villages of Surat district took out a rally in Sach in demanding closure of Gujarat Environment Protection Infrastructure Limited (GEPIL). The villagers were protesting ineffective functioning of the company which has been assigned the critical task of incinerating and treating several tons of hazardous waste received from industries in Ankleshwar and Vapi. It has been alleged that the company's incinerator has never functioned properly and the toxic waste was disposed into the sea through the Unnkhadi totally untreated. The court of chief judicial magistrate, Surat, has issued summons to the managing director and eight directors of Gujarat Enviro Protection and Infrastructure Limited (GEPIL) based on a complaint filed against them for allegedly illegally discharging toxic wastes. The officials have been asked to appear before the court on March 23, 2012. The complaint was filed by Gujarat Pollution Control Board (GPCB) regional officer (Surat) Mr. A.G. Patel. According to the complaint, GEPIL used to discharge untreated factory wastes directly into the main line of the Common Effluent Treatment Plant (CETP) at Sachin GIDC, which discharges polluted water into the Unn creek. Earlier, GPCB had slapped a temporary closure notice on the company after people from 32 affected villages took out a rally against GEPIL. ${ }^{25}$

\section{Case-2:TSDF proposal at Sachin, Surat (Gujarat)}

M/s. Thakorji Enviro Techno Pvt. Ltd. has proposed a Common Incineration Facility with waste heat recovery boiler over an area of $5600 \mathrm{~m}^{2}$ at GIDC Sachin, Dist. Surat, Gujarat for treatment and disposal of chemical waste (solid and aqueous) generated from various industries located in and around the area. The capital investment was Rs. 34.25Crores for Incineration (2tons/hr), Waste Heat Recovery Boiler (8tons/hr) and waste blending facility for co-processing (500tons/month) facility near Sonari Village at a distance of $1.9 \mathrm{~km}$ in North direction. For this set up, the environmental clearance is statuary requirement and EIA was completed by NABET accredited consultant. As per provision for EIA Notification 2006, the Public Consultation is required to conduct at site by State Pollution Control Board, hence the draft EIA was submitted to SPCB in March 2014 for the same as per norms. Public Consultation refers to the process by which the concerns of local affected persons and others who have plausible stake in the environmental impacts of the project or activity are ascertained with a view to taking into account all the material concerns in the project or activity design as appropriate. When the EIA/EMP reaches to public for incineration facility in Sachin GIDC, the NGO and villagers start opposing the same. They have protested against the proponent and submitted written application to Collector and other respective authorities against the project development due to dioxin. On the day, when public hearing was to be conducted, villages came with Lathi and made trouble to organizers; this made the Public consultation postponed by the collector till further action. The project is not started till 2018.

\section{Case-3:TSDF at Lothal (Gujarat)}

Industrial Waste Management Services (IWMS) has proposed a Common Integrated Landfill and Incineration Facility over an area of $2,26,089 \mathrm{~m}^{2}$ at Saragvala village in Dholka region of Gujarat for treatment and disposal of Industrial hazardous waste generated from various industries located in and around the Dist. Ahmedabad and Central Gujarat. The project site lies at $22^{\circ} 30^{\prime} 17.05^{\prime \prime} \mathrm{N}$ Latitude and $72^{\circ} 16^{\prime} 31.08^{\prime \prime} \mathrm{E}$ Longitude. The capital investment was Rs. 146.450Crores for landfill ( 2 Nos. having 15,00,000tons capacity) and incinerator (5tons/hr. of liquid/solid waste incineration) facility near Lothal Archaeological Museum at a distance of $3 \mathrm{~km}$ in North -West. For this set up, the environmental clearance is statuary requirement and EIA was completed by NABET accredited consultant. As per provision for EIA Notification 2006, the Public Consultation is required to conduct at site by State Pollution Control Board, hence the draft EIA was submitted to SPCB in November 2016 for the same as per norms. When the EIA/EMP reaches to public for such set up in the area near Lothal Archaeological Museum, some NGO and villagers start opposing the landfill and incineration set up. They have protested against the proponent and submitted written application to Collector and other respective authorities against the project development due to dioxin. Before the date of Public consultation, the collector has postponed the same till further information. The project is not started till 2018 .

\section{Conclusion}

Dioxins are a group of chemically-related compounds that are persistent environmental pollutants. Due to the omnipresence of dioxins, all people have background exposure, which is not expected to affect human health. However, due to the highly toxic potential, efforts need to be undertaken to reduce current background exposure. Although formation of dioxins is local, environmental distribution is global. Dioxins are found throughout the world in the environment. The highest levels of these compounds are found in some soils, sediments and food, especially dairy products, meat, fish and shellfish. Very low levels are found in plants, water and air. Short-term exposure of humans to high levels of dioxins may result in skin lesions, such as chloracne and patchy darkening of the skin, and altered liver function. Long-term exposure is linked to impairment of the immune system, the developing nervous system, the endocrine system and reproductive functions. Proper incineration of contaminated material is the best available method of preventing and controlling exposure to dioxins. It can also destroy PCB-based waste oils. The incineration process requires high temperatures, over $850^{\circ} \mathrm{C}$. For the destruction of large amounts of contaminated material, even higher temperatures like $1000^{\circ} \mathrm{C}$ or more are required. There is an urgent need to take care 
of release of toxic gasses from the hazardous waste treatment facilities and online monitoring of Dioxins within the chemical units.

\section{Acknowledgments}

None.

\section{Conflict of interest}

Author declares that he has no conflict of interest.

\section{References}

1. EPA. Information Sheet 1: Dioxin: Summary of the Dioxin Reassessment Science. US Environmental Protection Agency. Office of Research and Development; 2000. 2 p.

2. EPA. Estimating Exposure to Dioxin-like Compounds. US Environmental Protection Agency, Washington, DC. 1994.

3. Environment Canada. Criteria for the Selection of Substances for Virtual Elimination: Final Report of the ad hoc Science Group on Criteria. 1994 $25 \mathrm{p}$.

4. Stobiecki S, Silowiecki JC, Stociecki T. Disposal of pesticides as an alternative fuels in cement kilns. Plant protection institute Sosnicowice Poland; 2003.

5. Christel B. Incineration of hazardous waste in cement kilns. Waste management and research. 1989;7(4):351-361.

6. Karstensen KH. Formation and release of Pops in cement industry. 2nd ed. World business council for sustainable development, SINTEF; 2006.

7. Stanmore BR. The formation of dioxins in combustion systems. Combustion and flame. 2004;136(3):398-427.

8. Eduljee Gev. Dioxin formation and control in cement kilns. Austria: 1998.

9. Stieglitz L. Selected topics on the de novo synthesis of PCDD/PCDF on fly ash. Environmental engineering science. 1998;15(1):5-18.

10. Wikström E, Marklund S, Tysklind M. Influence of variation in combustion conditions on the primary formation of chlorinated organic micropollutants during municipal waste combustion. Environmental science and technology. 1999;33(23):4263-4269.

11. Shaub WM, Wing T. Dioxin formation in incinerators. Environmental science and technology. 1983;17(2):721-730.

12. EPA. Draft exposure and health reassessment of 2,3,7,8-tetrachlorodibenzo$p$-dioxin (TCDD) and related compounds. Environmental Protection Agency (EPA), Office of Research and Development (ORD), National Center for Environmental Assessment (NCEA), Washington, DC; 2000.
13. ATSDR. Toxicological Profile for Chlorinated Dibenzo-p-dioxins. U.S. Department of Health and Human Services, Agency for Toxic Substances Disease Registry (ATSDR), Atlanta, GA; 1998.

14. IARC. Polychlorinated dibenzo-para-dioxins and polychlorinated dibenzofurans. IARC monographs on the evaluation of carcinogenic risks to humans. International Agency for Research on Cancer (IARC), World Health Organization (WHO), Lyon, France; 1997.

15. EPA. Special Report on Environmental Endocrine Disruption: An Effects Assessment and Analysis. US Environmental Protection Agency. Washington, DC; 1997. $111 \mathrm{p}$.

16. Latchoumycandane $\mathrm{C}$, Mathur PP. Effects of vitamin $\mathrm{E}$ on reactive oxygen species-mediated 2,3,7,8-tetrachlorodi-benzo-p-dioxin toxicity in rat testis. J Appl Toxicol. 2002;22(5):345-351.

17. Gallagher M. Proposed Strategy to Continually Reduce Persistent Bioaccumulative Toxins (PBTS) in Washington State. Washington Department of Ecology; 2000. 65 p.

18. Swanson HI, Bradfield CA. The AH-receptor: Genetics, structure and function. Pharmacogenetics. 1993;3(5):213-230.

19. Fernandez-Salguero PM, Hilbert DM, Rudikoff S, et al. Aryl-hydrocarbon receptor-deficient mice are resistant to 2,3,7,8-tetrachlorodibenzop-dioxin-induced toxicity. Toxicology and Applied Pharmacology. 1996;140(1):173-179.

20. Zabel EW, Peterson RE. TCDD-like activity of 2,3,6,7-tetrachloroxanthene in rainbow trout early life stages and in a rainbow trout gonadal cell line (RTG-2). Environ Toxicol Chem. 1996;15(12):2305-2309.

21. Raloff J. Those old dioxin blues: some small fry are exquisitely sensitive models of dioxin vulnerability. Sci News banner. 1997;151(20):306-307.

22. Carey J, Cook P, Giesy J, et al. Eco-toxicological Risk Assessment of the chlorinated organic chemicals. SETAC Press, Pensacola, FL; 1998.

23. Rogowski D, Yake B. Addendum to Final Report: Screening Survey for Metals and Dioxins in Fertilizer Products and Soils in Washington State. Washington State Department of Ecology; 1999. 24 p.

24. Peters JM, Narotsky MG, Elizondo G, et al. Amelioration of TCDDinduced teratogenesis in aryl hydrocarbon receptor (AhR)-null mice. Toxicological Sciences. 1999;47(1):86-92.

25. Times of India. Villagers demand permanent closure of GEPIL. 2012. 